\title{
Forty-four Months' Experience in the Treatment of Leprosy with Clofazimine (Lamprene (Geigy)) *
}

\author{
E. J. SCHULZ \\ Westfort Institution and Department of Dermatology, \\ University of Pretoria, Pretoria, South Africa
}

\begin{abstract}
The author's experience in treating 123 patients with clofazimine is reported. Long-standing corticosteroid-dependent erythema nodosum leprosum (ENL) was adequately controlled after an average of 7 months of treatment with clofazimine. After an average of 16 months, recurrence of ENL was negligible. Early cases of ENL were easier to control. Patients with neuritis, and those with tuberculoid and borderline reactions and suspected dapsone resistance also responded favourably to clofazimine. A controlled trial over $2 \frac{1}{2}$ years indicated that while the addition of clofazimine to dapsone in the treatment of patients with lepromatous leprosy did not hasten bacillary clearance, the incidence of reactions was considerably decreased.
\end{abstract}

\section{Introduction}

A preliminary report of the results of the treatment of leprosy with clofazimine at Westfort was presented at a symposium held in London in 1968 (Waters, 1969) where previous observations of its efficacy both as an antibacterial and anti-inflammatory agent in leprosy were confirmed by numerous investigators. This report is an extension of these early findings and includes observations on 123 patients who received clofazimine for varying periods during 44 months. The dosage, duration of administration, and results of treatment with clofazimine are described under different headings, according to the purpose for which it was administered.

\section{Erythema Nodosum Leprosum (ENL)}

A total of 60 patients was treated. In the early stages only patients with severe long-standing corticosteroid-dependent ENL were included, but later patients with early, less severe forms of the reaction were treated as well. The purpose of the trial was to compare the duration of ENL and corticosteroid administration before and after treatment with clofazimine, the patients acting as their own controls. The patients were divided into 2 groups: (1) 31 with severe continuous ENL present for 4 months or longer, who had previously received prednisone in doses of 5 to $40 \mathrm{mg}$ daily almost continuously, and (2) 29 with relatively mild ENL present for less than 4 months who had been given prednisone for short periods only, if at all. A further 6 patients with severe long-standing ENL who

* Accepted for publication 24 August, 1971. 
refused clofazimine for psychological reasons relatively soon after starting treatment, are included as an additional control group. The average duration of previous anti-leprosy treatment in the 3 groups was 36, 27 and 48 months respectively. At the start of treatment with clofazimine there were 9 patients with negative bacteriological smears in the long-standing corticosteroid-dependent group, 7 in the short-term ENL group, and 2 in the "control" group.

The initial dose of clofazimine was usually $100 \mathrm{mg}$ daily, although some severe cases were started on $200 \mathrm{mg}$ daily. The dose was increased by $100 \mathrm{mg}$ daily at intervals of 1 to 2 weeks to a maximum of $400 \mathrm{mg}$ daily according to the patient's response. It had been decided not to exceed this dose in view of possible gastrointestinal disturbance. When the ENL had improved, the dose of prednisone was gradually decreased and then stopped. In those patients in whom the dosage of dapsone had been decreased (or in rare cases, stopped) it was gradually increased until the routine dose of $300 \mathrm{mg}$ weekly was again reached. ENL was considered to be under control when there were no, or only negligible, attacks and prednisone had been stopped. After the ENL had been under control for at least a month or more, depending on previous severity, the dose of clofazimine was gradually decreased and then stopped.

\section{RESULTS}

The average duration of ENL and prednisone administration, before and after clofazimine was started, the time needed for adequate control and the total duration of clofazimine administration are summarized in Table 1. At the time of writing, in 25 of the 31 patients in the group with severe long-standing ENL treatment with clofazimine had been stopped for periods varying from 1 week to 34 months, after an average treatment period of 16 months. In 6 of these patients, clofazimine was first stopped after about 8 months but had then to be restarted for ENL, which recurred within a few days to 7 months after clofazimine had last been given. In one exceptional case ENL recurred after an initial treatment period of 24 months. In the group of 29 patients with milder forms of ENL, the reaction at the time of writing is under control in all, but 15 are still receiving clofazimine and the total duration of treatment will therefore be longer than the present average of $5 \frac{1}{2}$ months.

TABLE 1

Results of treatment of ENL with clofazimine

\begin{tabular}{lccccc}
\hline \multicolumn{1}{c}{ Group } & $\begin{array}{c}\text { Previous } \\
\text { ENL } \\
\text { (months) }\end{array}$ & $\begin{array}{c}\text { Previous } \\
\text { prednisone } \\
\text { (months) }\end{array}$ & $\begin{array}{c}\text { Duration } \\
\text { clofazimine } \\
\text { (months) }\end{array}$ & $\begin{array}{c}\text { Prednisone } \\
\text { stopped } \\
\text { (months) }\end{array}$ & $\begin{array}{c}\text { Adequate } \\
\text { control } \\
\text { (months) }\end{array}$ \\
\hline $\begin{array}{l}\text { Long-standing corticosteroid- } \\
\text { dependent ENL (31 patients) }\end{array}$ & 20 & 17 & 16 & 4.75 & 6.75 \\
$\begin{array}{l}\text { Long-standing corticosteroid- } \\
\text { dependent ENL-clofazimine } \\
\text { refused (6 patients) }\end{array}$ & 16 & 15 & 2.25 & 17 & $23+$ \\
$\begin{array}{l}\text { Short-term ENL, not } \\
\text { corticosteroid-dependent }\end{array}$ & 2 & 0.5 & $5.5+$ & 1.0 & 3.5 \\
\hline \begin{tabular}{l}
29 patients) \\
\hline
\end{tabular} & & & & & \\
\hline
\end{tabular}


The maximum daily dose of clofazimine required was $100 \mathrm{mg}$ in 9 cases, $200 \mathrm{mg}$ in $9,300 \mathrm{mg}$ in 31 and $400 \mathrm{mg}$ in 11 patients. Although the general tendency was for the patients with the milder ENL of more recent onset to respond to smaller doses, 3 of the patients requiring $400 \mathrm{mg}$ were in this group. Patients who had in addition acute arthritis ( 5 cases) and ulcerating lesions of the erythema multiforme type ( 2 cases) were the most difficult to control and required systemic corticosteroids as well. Tibial pains following attacks of ENL did not appear to respond to clofazimine and were treated with anti-malarials and analgesics. In some patients the ENL became worse during the first few weeks of treatment, and 1 patient developed acute arthritis after 5 months of treatment while receiving $400 \mathrm{mg}$ of clofazimine daily. Four patients developed neuritis while on low doses of clofazimine (100 mg daily and $300 \mathrm{mg}$ weekly), one in the first month and the others after 10,12 and 13 months of treatment, respectively, when the ENL was already under control. However, in 8 patients who had neuritis in addition to ENL from the start, the neuritis improved more quickly than the ENL.

At the end of the treatment period, the bacteriological index (BI) was negative in 24 of the 31 patients in the long-standing corticosteroid-dependent group and in 6 of the 29 patients in the short-term ENL group. Two patients died of amyloid nephrosis-one after $6 \frac{1}{2}$ months of treatment with clofazimine during which time the ENL improved but arthritis remained a problem, and the other 8 months after he had last had clofazimine which had been given for 7 months (see section "Laboratory Examinations" below).

\section{Neuritis}

Of the 13 patients (5 with lepromatous, 4 borderline, and 4 tuberculoid leprosy) who were treated with clofazimine for neuritis which had been continuous for an average of $2 \frac{1}{2}$ months, all but 4 had taken prednisone for an average of $1 \frac{1}{2}$ months with inadequate response. All had previously been treated with dapsone except for one with tuberculoid leprosy who was given only clofazimine from the start. Dapsone was continued in 7 of the patients treated with clofazimine, while in those at first treated with clofazimine alone dapsone was reintroduced and gradually increased to $300 \mathrm{mg}$ weekly when the neuritis was under control. Of these patients, 8 had in addition either ENL, arthritis, or acute reactions in skin lesions. The dose of clofazimine was regulated in the same way as for ENL.

\section{RESULTS}

The average time needed for adequate control of the neuritis was $3 \frac{1 / 2}{2}$ months and prednisone was stopped after an average of $1 \frac{1 / 2}{2}$ months. The response in the different types of leprosy was similar. By the time of writing this report 9 patients had already stopped taking clofazimine for periods of 3 to 14 months, after an average duration of treatment of 9 months. Neuritis was under adequate control in the remaining 4 patients. So far neuritis has recurred in 2 of the 9 patients, 3 and 6 months respectively after clofazimine was stopped.

The maximum daily dose of clofazimine given was $100 \mathrm{mg}$ in 1 case, $200 \mathrm{mg}$ in 3 , and $300 \mathrm{mg}$ in 8 patients. In one of the borderline patients the dose was increased to $400 \mathrm{mg}$ daily for an acute erythema-multiforme type of ENL after the neuritis had already improved. In 2 patients with tuberculoid leprosy acute 
reactions in skin lesions and oedema of the hands and feet developed 2 months after starting clofazimine while taking 100 and $200 \mathrm{mg}$ respectively daily. One of these patients developed bilateral foot-drop while taking $200 \mathrm{mg}$ daily 4 months after treatment was started, but this improved remarkably during the next 6 months. An additional patient developed foot-drop one month after starting clofazimine, also while receiving $200 \mathrm{mg}$ daily. The foot-drop improved within a month, but he later developed an acute reaction in skin lesions after the dose had been reduced to $100 \mathrm{mg}$ daily. In view of the fact that more than half the patients in this neuritis group had additional reactions, the duration of clofazimine treatment may have been longer than otherwise required had they all had neuritis alone.

\section{Acute Cutaneous Reactions}

Eleven patients ( 6 with borderline and 5 with tuberculoid leprosy) who had acute swelling of skin lesions, accompanied in 6 cases by oedema of the face, hands and feet, were given clofazimine. Treatment was started within 1 to 4 weeks of the onset of the reaction. Dapsone had been stopped in 10 of these patients and the dose reduced in the 11 th. Two patients had received prednisone for 1 week before clofazimine was started and in 4 prednisone was started at the same time as clofazimine. The dosage of clofazimine was similar to that given for ENL.

\section{RESULTS}

The average duration of clofazimine administration before the reactions were under control was 3 months in both borderline and tuberculoid patients. In the 6 patients who received prednisone, this was stopped after 2 to 5 weeks. Eight of the 11 patients were still receiving clofazimine at the time of writing, but all reactions were well controlled and it is unlikely that the present average time of administration, i.e. $61 / 2$ months, will be greatly exceeded. The maximum daily dose of clofazimine was $100 \mathrm{mg}$ in 5 patients, $200 \mathrm{mg}$ in $1,300 \mathrm{mg}$ in 4 and $400 \mathrm{mg}$ in 1 patient. Treatment with dapsone was resumed once the reaction was under control, the dosage being gradually increased to $300 \mathrm{mg}$ weekly while the dose of clofazimine was being decreased.

\section{Suspected Dapsone Resistance}

Dapsone resistance, which was diagnosed on the lack of clinical, bacteriological and/or histological response to standard treatment with the drug (300 mg weekly since 1966 and $600 \mathrm{mg}$ weekly before then) was suspected in 6 patients with lepromatous leprosy who had previously received dapsone for 4 to 10 years. Clofazimine had so far been administered for 2 to 26 months in a dose of $100 \mathrm{mg}$ daily to 4 of these patients and $300 \mathrm{mg}$ weekly to 2 . All 6 patients showed improvement in the bacterial index (BI) by the 7th month of treatment. In the patient who has had only 2 months of treatment so far, some flattening of lepromatous nodules has already been noted. In 2 patients with borderline leprosy who had not responded satisfactorily to treatment with dapsone for $2^{1 / 2}$ and $6 \frac{1}{2}$ years respectively, the BI became negative after a year of treatment with clofazimine, $100 \mathrm{mg}$ daily, although the skin lesions took longer to clear. Treatment has been continued for 2 and 3 years respectively. Two patients with tuberculoid leprosy, who still had depigmented and slightly infiltrated macules 
with histological evidence of activity after 3 years' treatment with dapsone, have been given clofazimine for 8 and 11 months so far, the first, an adult, receiving $100 \mathrm{mg}$ daily and the second, a child of 10 years, $300 \mathrm{mg}$ weekly. Improvement was noted after 3 months of treatment and the lesions have flattened and repigmented. All 10 patients continued to take dapsone.

\section{Other Indications for Clofazimine}

Of 2 patients with extensive lepromatous ulcerations and one with laryngeal involvement who were not responding to dapsone, all 3 improved considerably after clofazimine was given in addition in a dose of $100 \mathrm{mg}$ daily. These 3 patients had had intermittent treatment with dapsone for 23, 24, and 17 years respectively, were still bacteriologically positive and could probably be classified as cases of dapsone resistance. The ulcers started to show improvement after 2 months and the laryngeal stenosis by the end of the 3rd month of treatment. Subsequently the BI has also markedly improved in all 3 patients.

Clofazimine was given instead of dapsone when it became necessary to treat a patient with lepromatous leprosy with vincristine and cyclophosphamide for an inoperable bronchogenic carcinoma. The sulphone was stopped, as previous observations (Davison et al., 1964) indicated that it protects the bone-marrow from the leucopaenic effect of cyclophosphamide and could thus inhibit its anticancerous action. In the year prior to the patient's death from carcinoma the leprosy infiltrations and the BI improved steadily.

Another 3 patients with lepromatous leprosy were given clofazimine at their own request. The first, who had mild intermittent ENL and neuritis present for a year, became symptom-free after 4 months' treatment with $100 \mathrm{mg}$ of clofazimine daily. He took $300 \mathrm{mg}$ weekly for a further 14 months while continuing with dapsone, during which time he said that ulcers resulting from burns healed more rapidly than before he had taken clofazimine. The second patient had mild recurrent ENL and brawny oedema of the extremities. After 32 months' treatment with clofazimine, $300 \mathrm{mg}$ weekly in addition to dapsone, there has been no recurrence of ENL but no demonstrable decrease in the swelling. He does not want to stop the clofazimine because he says he feels much better while taking it. The 3 rd patient, who had been given thiambutosine for $1 \frac{1 / 2}{2}$ years as he regularly developed a rash whenever he took dapsone, requested clofazimine for neuritic pains and numbness of the extremities. After 8 months of clofazimine, $100 \mathrm{mg}$ daily, his symptoms improved considerably. There was some objective improvement in the first 2 patients but subjective improvement was considerable in all, probably largely for psychological reasons.

\section{Combination of Clof azimine and Dapsone in Lepromatous Leprosy}

The purpose of this part of the trial was to ascertain whether the addition of clofazimine to standard treatment with dapsone would hasten clinical and bacteriological clearance in patients with lepromatous leprosy. It was started in 2 groups, each of 16 patients, all of whom had previous treatment with dapsone alone for an average of $81 / 2$ months. All patients had diffuse infiltration of the skin with strongly positive smears. Half of them had nodular lesions in addition. The patients were divided into 2 groups, equal as far as possible in regard to duration of previous treatment, lesion index (LI), bacterial index (BI), and morphological 
index (MI).* All patients received $300 \mathrm{mg}$ of dapsone weekly and one group $100 \mathrm{mg}$ of clofazimine daily in addition. At the start of the trial the LI, BI and MI values in the group given dapsone alone were $6.5,3.25$ and $1.5 \%$ respectively, and $7.5,3.5$ and $2.0 \%$ in the group receiving clofazimine in addition; 6 patients in each group had reactions, mainly in the form of ENL.

\section{RESULTS}

At the end of 18 months, 3 patients in the group given dapsone alone had severe reactions which were inadequately controlled by corticosteroids; they were removed from the trial as it was thought that treatment with clofazimine was warranted. Another 4 patients subsequently defected from the trial and by the end of $2 \frac{1}{2}$ years there were 10 patients left in the group receiving dapsone only, and 15 in the group on dapsone plus clofazimine. The MI was $0 \%$ in both groups by the end of 10 months. Subsequently until the end of the trial there were 2 patients in each group who had occasional intact bacilli. The reduction in the LI and $\mathrm{BI}$ in the patients remaining in the trial at the end of 18 months and 30 months are summarized in Table 2. At 22 months, 8 smears were counted to ascertain how examining more sites would affect the final results. The average BI was $5 \%$ higher when 8 sites were counted instead of 4 , a difference which was not considered to be significant. From Table 3 it can be seen that whereas the number of patients with reactions decreased in the group receiving clofazimine, they increased in those given dapsone alone. If the 3 patients removed from the

TABLE 2

$\%$ reduction in $L I$ and $B I$ in lepromatous leprosy treated with dapsone and dapsone plus clofazimine

\begin{tabular}{ccccc}
\hline Group & \multicolumn{2}{c}{ Lesion index } & \multicolumn{2}{c}{ Bacteriological index } \\
\cline { 2 - 4 } & 38 months & 50 & 39 & 50 months \\
\hline $\begin{array}{l}\text { Dapsone only } \\
\begin{array}{l}\text { Dapsone plus } \\
\text { clofazimine }\end{array}\end{array}$ & 45 & 52 & 47 & 58 \\
\hline
\end{tabular}

TABLE 3

$\%$ ENL on treatment with dapsone and dapsone plus clofazimine

\begin{tabular}{cccc}
\hline Group & Initial & 18 months & 30 months \\
\hline Dapsone only & 38 & 71 & 50 \\
$\begin{array}{l}\text { Dapsone plus } \\
\text { clofazimine }\end{array}$ & 38 & 19 & 27 \\
\hline
\end{tabular}

* These parameters were calculated as follows: LI: The sum of infiltrations, nodules and plaques or macules graded from 0 to 3 in 4 sites (face, ears, trunk and limbs); BI: The average of smears from 4 sites (ear, forehead, cheek and arm) graded according to the Dharmendra method from 0 to 4 ; MI: The percentage of solid, uniformly staining, bacilli of adequate length in each smear. 
dapsone group at 18 months are included in the final analysis, the percentage of reactions in this group would be $60 \%$, instead of $50 \%$ as given in the table. In the patients who still had reactions while taking $100 \mathrm{mg}$ clofazimine daily, the dose was subsequently increased to control ENL.

\section{SIDE-EFFECTS}

Of the 123 patients treated with clofazimine 108 were Bantu, 8 Coloured, 5 White, and 2 Indian. All showed pigmentation varying from pink to very dark brown, almost black, being most marked in skin infiltrations and depending on the original skin colour, dose and duration of treatment. Marked conjunctival pigmentation was seen in only 5 patients, but 10 patients complained of pruritus, either generalized or confined to the face, without visible rash. In other cases pruritus was an early manifestation of ichthyosis, which was marked in $30 \%$ of patients receiving clofazimine. It was either generalized or localized to skin lesions or to the shins, appeared when the disease was resolving and subsequently desquamated. In 8 patients a rash developed during treatment, but this could not definitely be ascribed to clofazimine as it cleared with continued administration; in 5 of the 8 it took the form of non-specific, itching, follicular and papular eruptions mainly confined to the face, in 2 it appeared to be seborrhoeic dermatitis and in 1 erythema multiforme. Three patients developed a monilial perlèche which cleared after 1 month's treatment with gentian violet. Three patients who were given clofazimine for ENL developed abdominal symptoms consisting of pain and either constipation or diarrhoea, severe enough to stop treatment. They had been treated for 12,13 and 18 weeks respectively and the maximum daily dose was $300 \mathrm{mg}$ in 2 cases and $400 \mathrm{mg}$ in the $3 \mathrm{rd}$. Weight loss was so marked in one patient that he was admitted to hospital. All routine investigations, including X-ray examination, were negative, but jejunal biopsy was not done; this patient recovered soon after clofazimine was stopped. Two of these patients subsequently tolerated clofazimine in reduced doses over several months while in 10 other patients who complained of transient abdominal pains and nausea in the early stages, treatment with clofazimine was not interrupted.

\section{Laboratory Examinations}

Blood cell counts, liver function tests, blood urea level and urinalysis were carried out only in the trial in which clofazimine was given in addition to dapsone to lepromatous patients; there was no evidence of any toxicity. By the end of the $2 \frac{1}{2}$-year period special investigations in the group receiving clofazimine showed fewer abnormalities than those in the group given dapsone alone. Indeed the haemoglobin level was higher, leucocytosis was reduced and serum protein electrophoretic patterns deviated less from the normal in the clofazimine-treated group.

Full post-mortem details are available in 2 patients who were treated with clofazimine for ENL and who died after developing a nephrotic syndrome with acute renal failure. The first had received clofazimine for $6 \frac{1}{2}$ months (maximum daily dose $300 \mathrm{mg}$ ) and died within a week of the last dose, while the second patient, who had had clofazimine for 7 months (maximum daily dose $200 \mathrm{mg}$ ) died 8 months after the last administration. In both cases the picture was that of healing lepromatous leprosy, with no demonstrable bacilli, and widespread secondary amyloidosis with marked renal involvement. In the first patient, who 
died while still in a state of reaction, there was in addition marked renal tubular necrosis and small superficial ulcerations were found in the mucosa of the stomach and small bowel. In the second patient, who had last had clofazimine 8 months before death, frozen sections examined under polarized light revealed numerous crystals in the epithelial cells of the cortical tubules of the kidneys which resembled crystals of clofazimine, but these were not identified by further investigation. The bone-marrow was normal in both patients.

\section{CLOFAZIMINE DURING PREGNANCY}

Five patients took clofazimine during pregnancy, including the first trimester, but there was no sign of teratogenicity in any of the offspring. Post-mortem examination of 2 infants who died, one of prematurity and antemortem haemorrhage and the other of gastro-enteritis, showed no evidence of drug toxicity. None of the babies was hyperpigmented at birth. As all the mothers had lepromatous leprosy, none of the babies was breast-fed.

\section{Discussion}

In our patients with severe long-standing corticosteroid-dependent ENL, adequate control (i.e., attacks were negligible or no longer incapacitating and steroids were no longer required) was obtained after about 7 months of treatment with clofazimine. A further 9 months of treatment was necessary to prevent recurrence. In previously reported trials ENL was brought under control after shorter periods (Imkamp, 1968; Karat et al., 1970; Languillon, 1970). Treatment for longer periods (up to 24 months) was however required to prevent recurrence in some patients (Atkinson et al., 1967; Warren, 1970). Like Morgan (1970) we found that in a few patients with severe ENL the reaction became worse during the initial stages of treatment with clofazimine and that patients who were corticosteroid-dependent were slower to respond. It has been suggested that clofazimine should not be stopped while the BI remains high (Warren, 1970). This does not seem to be a reliable guide to the duration of treatment. In our patients with long-standing corticosteroid-dependent ENL who were treated for an average period of 16 months the BI naturally decreased during this period, but at the end almost a quarter of them still had positive smears. We have also seen patients in whom severe ENL has recurred for as long as 2 years af ter the BI became negative. In our patients with milder forms of ENL who were not corticosteroid-dependent, the BI did not change during the short treatment period of $3 \frac{1}{2}$ months in which the ENL came under control. It is of course impossible to tell whether the ENL in these patients would have run a shorter course even without treatment with clofazimine. Pettit (1967) found that clofazimine in a dose of $100 \mathrm{mg}$ daily over a long period (14 months) had no anti-inflammatory effect in severe cases of ENL. Our findings in a trial over $2 \frac{1}{2}$ years in which lepromatous patients given clofazimine, $100 \mathrm{mg}$ daily, in addition to dapsone were compared with patients treated with dapsone alone, indicated that while ENL was not completely suppressed on this dose, the incidence of ENL was considerably reduced. There is general agreement that the response of ENL to clofazimine depends on an adjustment of the dose to the severity of the reaction (Waters, 1969). So far, Gatti et al. (1970) are the only authors who have found that the incidence of ENL is higher on large doses (300 mg daily) than -on smaller doses (100 mg daily). Of our 31 patients 4 with severe ENL were not adequately controlled on 
clofazimine, $400 \mathrm{mg}$ daily; only one of these patients was above average weight. Because our own experience and that of Atkinson et al. (1967) indicates that gastro-intestinal disturbances are readily reversible, we now give $500 \mathrm{mg}$ of clofazimine daily when necessary. Dapsone was continued throughout the treatment period and our aim was to stop the clofazimine as soon as the ENL was under control. As clofazimine is excreted extremely slowly (Vischer, 1969), it was unexpected to find a few early recurrences of ENL after the close of a long period of administration of the drug. Other authors have had similar experiences (Atkinson et al., 1967; Warren, 1970). In our patients neuritis was adequately controlled after an average of $3 \frac{1}{2}$ months of treatment with clofazimine. Two patients developed foot-drop while on the relatively low dose of $200 \mathrm{mg}$ daily. Warren (1970) found recurrence of neuritis af ter many months of treatment with clofazimine; she ascribed this to the fact that the dose was not high enough. In her patients improvement in sensory and motor function appeared to be enhanced during treatment with clofazimine. Our impression is that patients with neuritis and acute cutaneous reactions in tuberculoid and borderline leprosy do better on clofazimine than on dapsone. We now start all patients with these presenting features on clofazimine alone in a dose of 100 to $200 \mathrm{mg}$ daily. Dapsone is introduced gradually after several months when the reaction has been controlled. Browne (1965) found that the speed of bacterial clearance was slightly greater in patients who had been given dapsone in addition to clofazimine. In the earlier stages of our controlled trial on patients with lepromatous leprosy, those receiving clofazimine plus dapsone appeared to be doing better than those on dapsone alone, but clinical and bacteriological improvement was the same in the two groups after $2 \frac{1}{2}$ years of treatment. Skin pigmentation was seen in all patients given clofazimine and was initially objected to by a few young females, who however later accepted it. Transient rashes were encountered but none required cessation of treatment. Our findings are similar to those of Gatti et al. (1970), who found that the skin becomes xerodermic or frankly ichthyosiform as the lesions resolved. In a previous survey ichthyosis was found in $10 \%$ of all patients at Westfort (Schulz, 1965). During this trial marked ichthyosis was found in 30\% of patients who received clofazimine. This higher incidence may be due to the fact that the ichthyosis is more visible as a result of hyperpigmentation or because the drug has a drying effect on the skin.

Clofazimine accumulates in the cells of the reticulo-endothelial system where it has been seen in experimental animals to be deposited in the form of crystals (Conalty and Jackson, 1962; Shepard and Chang, 1964; Vischer, 1969). Crystals have been found in the lamina propria of the jejunum and in the bone-marrow in patients treated for leprosy (Atkinson et al., 1967). In 2 patients examined post mortem there were no pathological changes suggesting drug toxicity in any of the organs. The superficial ulcerations in the small bowel in the first patient were not associated with visible crystals and were ascribed to uraemia. Crystals, similar in shape to those of clofazimine, were found in the renal cortical tubules in the second patient. As the patient had last taken the drug 8 months before death, and as the crystals were present in epithelial cells rather than in association with macrophages, it is extremely unlikely that they were due to clofazimine. It has been shown in experimental animals that clofazimine is transmitted to a slight extent to the foetus via the placenta (Vischer, 1969). The lack of hyperpigmentation of the skin and of teratogenicity in infants born to our patients treated with clofazimine during pregnancy, suggest that transplacental transmission of the drug in the human subject is not of clinical significance. 


\section{Acknowledgements}

Thanks are due to the Secretary for Health, State Health Department, Republic of South Africa, for permission to publish this article: to Professor I. W. Simson, Department of Pathology, University of Pretoria for post-mortem and histological examinations, to the Superintendent and staff of Westfort Institution for assistance, and to Dr. Dudley Jacobs, Medical Department, Ciba-Geigy, South Africa, for advice and supplies of clof azimine.

\section{References}

Atkinson, A. J., Sheagren, J. N., Barba Rubio, J. and Knight, V. (1967). Evaluation of B 663 in human leprosy. Int. J. Lepr. 35, 119.

Browne, S. G. (1965). Treatment of leprosy with B 663. Appraisal of the pilot trial after three years. Lepr. Rev. 36, 13.

Conalty, M. L. and Jackson, R. D. (1962). Uptake by reticulo-endothelial cells of the riminophenazine B 663 (2-P-Chloroanilino-5-P-chlorophenyl-3 : 5-dihydro-3-isopropylimophenazine). Br. J. exp. Path. 43, 650.

Davison, A. R., Schulz, E. J., Falkson, G. and Egnal, M. L. (1964). Effect of cyclophosphamide on leprosy. Competitive action of cyclophosphamide and dapsone. Lancet ii, 1138.

Gatti, J. C., Cardama, J. E., Balina, L. M., Crespi, H. G. Bianchi, O., Santabaya, E. and Farina, M. H. (1970). Treatment of leprosy with a phenazine derivative (B 663 or G 30 320)-clofazimine. Lepr. Rev. $41,89$.

Imkamp, F. M. J. H. (1968). A treatment of corticosteroid-dependent lepromatous patients in persistent erythema nodosum leprosum. A clinical evaluation of G 30320 (B 663). Lepr. Rev. 39, 119.

Karat, A. B. A., Jeevaratnam, A., Karat, S. and Rao, P. S. S. (1970). Double-blind controlled clinical trial of clofazimine in reactive phases of lepromatous leprosy. Br. med. J. i, 198.

Languillon, J. (1970). Action de deux nouveaux produits, la thalidomide et le B 663, sur les formes réactionnelles de la maladie de Hansen. Méd. Trop. 29, 497.

Morgan, J. (1970). Management of steroid-dependency with clofazimine [Lamprene or B 663 (Geigy).] Lepr. Rev. 41, 229.

Pettit, J. H. S. (1967). The treatment of erythema nodosum leprosum with B 663. A controlled study. Int. J. Lepr. 35, 11.

Schulz, E. J. (1965). Ichthyosiform conditions occurring in leprosy. Br. J. Derm. 77, 151.

Shepard, C. C. and Chang, Y. T. (1964). Activity of anti-tuberculosis drugs against Mycobacterium leprae. Studies with experimental infection of mouse footpads. Int. J. Lepr. 32, 260.

Vischer, W. A. (1969). The experimental properties of G 30320 (B 663)-a new anti-leprotic agent. Lepr. Rev. 40, 107.

Warren, A. G. (1970). The use of B 663 (clofazimine) in treatment of Chinese leprosy patients with chronic reaction. Lepr. Rev. 41, 74.

Waters, M. F. R. (1969). G 30320 or B 663-Lamprene (Geigy). A working party held at the Royal Garden Hotel, London, September 1968. Lepr. Rev. 40, 21. 